\title{
Cyto-histopathological study of Mediastinal lesions
}

\section{Bhattarai $\mathrm{N}^{1}$}

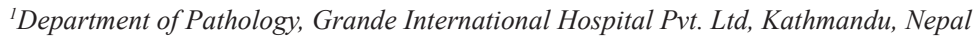

\section{Keywords: \\ Mediastinal lesions; \\ Thymoma; \\ Non-hodgkin's Lymphoma}

\begin{abstract}
Background: Broad ranges of non-neoplastic and neoplastic lesions are encountered in mediastinum depending on the patient's age and anatomical site. This study was performed to review our institutional experience of mediastinal masses and to compare the results with various other studies.
\end{abstract}

Materials and Methods: This was a retrospective study conducted on 112 patients with mediastinal masses who underwent fine needle aspiration cytology and/or biopsy from 14th April 2009 to 4th March 2014 in Department of Pathology, Institute of Medicine, Tribhuvan University Teaching Hospital.

Results: Out of 112 cases, 70 cases $(62.5 \%)$ were benign, 38 cases $(33.92 \%)$ malignant and 4 cases (3.57\%) were inconclusive. Mean age of presentation was 34.94 yrs with male to female ratio of 1.2:1. Ninety-nine cases $(88.4 \%)$ were seen in anterior compartment, 12 cases $(10.7 \%)$ in posterior compartment and 1 case $(0.9 \%)$ in middle compartment. Thymoma ( 26 cases) was the most common lesion followed by Non Hodgkin lymphoma (17 cases) and germ cell tumor (16 cases).

Conclusion: Mediastinal lesions occur more commonly in males with higher frequency of benign lesions, among which thymoma is the predominant lesion.

\section{INTRODUCTION}

The mediastinum can be defined as those tissue and organs that occupy thoracic cavity between pleural cavities and lung laterally, between sternum anteriorly and vertebral column posteriorly and from thoracic inlet down to diaphragm. ${ }^{1}$ It is usually divided into anterior, middle and posterior compartments to help categorize tumors and disease according to their site of origin and location. ${ }^{2}$

\section{Correspondence:}

Dr. Narendra Bhattarai, MBBS, $M D$

Department of Pathology, Grande International Hospital Pvt. Ltd.,

Dhapasi, Kathmandu Nepal

Email: narenbhatrai@gmail.com
Specific tumor types show proclivities to occur in specific compartments. ${ }^{1}$ The relative frequency of various lesions are considerably different in these compartments and also in different age groups. ${ }^{3}$

Many mediastinal masses are serendipitously discovered on chest radiograph obtained for other reasons. Some patients will come to clinical attention with vague chest complaints or with sign and symptoms related to compression or invasion of mediastinal structure. ${ }^{2}$ FNA is a good diagnostic tool in lesions of mediastinum as a first attempt to tissue diagnosis. ${ }^{4}$ Cutting needle techniques are used when FNA diagnosis is uncertain. ${ }^{5}$ This study was done to review and 
analyze all the cases of mediastinal lesions of the last 5 years period.

\section{MATERIALS AND METHODS}

This is a retrospective descriptive study performed on 112 patients with mediastinal lesion who underwent FNAC and/or tissue biopsy over 5 years period from $14^{\text {th }}$ April 2009 to 4th March 2014 in Department of Pathology, Institute of Medicine, Tribhuvan University Teaching Hospital. Permission was obtained from institutional review committee. FNAC was done using 23 gauge needle attached to $10 \mathrm{ml}$ syringe. Cytological material was smeared on clean glass slide. The smear was immediately immersed in 95\% alcohol for papanicolaou stain and air-dried for Giemsa stain. The surgical specimen were formalin fixed, routinely processed and stained with Hematoxylin and Eosin stain. The slides were reviewed by pathologist and diagnosis was made. Computer database in the department was used to extract all the information pertinent to the cases. Statastical analysis was performed using Epi info wherever required.

\section{RESULTS}

Out of 112 patients, 39 underwent FNAC, 62 underwent histopathological examination and in 11 cases both FNAC and histopathological examination was done.

Sixty-three cases (56.25\%) were males, 49(43.75\%) were females with male female ration of 1.2:1. Age range was between 4 months to 82 years with mean age of 34.94 years. (Table 1) Seventy cases (62.5\%) were benign, while 38 cases $(33.9 \%)$ were malignant and 4 cases $(3.6 \%)$ were inconclusive. Anterior mediastinum was the most common site $(n=99 ; 88.4 \%)$ followed by $10.7 \%(n=12)$ in middle mediastinum and $0.9 \%(\mathrm{n}=01)$ of the lesions were in posterior mediastinum.

Out of 112 cases, 70 (62.5\%) were benign, 38 (33.9\%) were malignant and $4(3.5 \%)$ were inconclusive. Most common lesion was thymoma $(n=26 ; 23.2 \%)$ followed by nonhodgkin lymphoma $(\mathrm{n}=17 ; 15.2 \%)$. Detail diagnoses

Table 1: Frequency of mediastinal tumors in different age groups:

\begin{tabular}{lcc}
\hline \multicolumn{1}{c}{ Age } & Frequency (\%) & Malignancy rate \\
\hline 1st decade(0-9) & $8(7.1 \%)$ & $25 \%$ \\
2nd (10-19) & $17(15.2 \%)$ & $53 \%$ \\
3rd (20-29) & $24(21.4 \%)$ & $37.5 \%$ \\
4th (30-39) & $18(16.1 \%)$ & $16.6 \%$ \\
5th (40-49) & $16(14.3 \%)$ & $31.3 \%$ \\
6th (50-59) & $11(9.8 \%)$ & $18.2 \%$ \\
7th (60-69) & $10(8.9 \%)$ & $30 \%$ \\
8th above (70 and above) & $8(7.2 \%)$ & $62.5 \%$ \\
\end{tabular}

Table 2: Different mediatinal lesions and their frequencies

\begin{tabular}{|c|c|c|c|}
\hline No. & Lesion & No. of cases & Percentage(\%) \\
\hline 1 & Thymoma & 26 & $23.2 \%$ \\
\hline 2 & NHL & 17 & $15.2 \%$ \\
\hline 3 & Germ cell tumors & 16 & $14.3 \%$ \\
\hline \multirow[t]{4}{*}{4} & Lymphadenitis & 14 & $12.5 \%$ \\
\hline & Granulomatous lymphadenitis & 5 & \\
\hline & $\begin{array}{l}\text { Necrotizing granulomatous } \\
\text { lymphadenitis }\end{array}$ & 7 & \\
\hline & Reactive lymphadenitis & 2 & \\
\hline 5 & Neural tumors & 10 & $8.9 \%$ \\
\hline 6 & Metastatic tumors & 9 & $8 \%$ \\
\hline 7 & Others & 8 & $7.1 \%$ \\
\hline 8 & Sarcoma & 4 & $3.6 \%$ \\
\hline 9 & Cysts & 4 & $3.6 \%$ \\
\hline 10 & Inconclusive & 4 & $3.6 \%$ \\
\hline
\end{tabular}

of midiastinal lesions are tabulated in table 2. Most mediastinal lesion $21.4 \%$ were identified in third decade of life. The highest incidence of malignancy occurred in eighth decade and above followed by second decade of life. Non Hodgkin lymphoma was most common in second and third decade while Germ cell tumors in second-fourth decade of life. Metastatic tumors were common in later decades and thymoma in fourth to sixth decade of life.

Out of 112 cases with FNAC diagnosis, 11 cases were available for correlation with histopathology. Detail of these correlations is shown in table 3 . From this data, overall sensitivity of FNAC in diagnosing mediastinal lesion is $63.6 \%$ and specificity in diagnosing malignant lesion is $100 \%$.

\section{DISCUSSION}

The types of mediastinal mass examined in this study broadly reflect range of pathological conditions seen in our clinical practice. Biopsy of mediastinal mass can be performed by variety of techniques ranging from FNAC to surgical procedures allowing resection or biopsy. ${ }^{6} \mathrm{~A}$ major advantage of FNAC is that immediate cyotological examination of specimen is possible. ${ }^{5}$

Demographics in this study is similar to those in previous reported series with wide range of age (4 months-77 years) and mean age of 34.94 yrs. In a study of Shabb N.S. et.al age range was 10-72 yrs and similar to their study our study also showed male predominance. ${ }^{4}$

Sixty one and half $\%$ cases in our study were benign followed by $33.9 \%$ malignant. This was in contrast to study by Zafar N. et.al ${ }^{7}$ who detected higher rate of malignancy about $74 \%$ but show concordance with study done by Strollo 


\begin{tabular}{|c|c|c|c|c|}
\hline No. & Age/sex & Location & FNAC diagnosis & Histopathological diagnosis \\
\hline 1 & $30 / \mathrm{F}$ & Anterior & Inconclusive & Thymoma \\
\hline 2 & $36 / \mathrm{F}$ & Posterior & Chondrosarcoma & Chondrosarcoma \\
\hline 3 & $1 / \mathrm{M}$ & Anterior & Inconclusive & Thymoma \\
\hline 4 & $70 / \mathrm{M}$ & Anterior & Inconclusive & Thymoma \\
\hline 5 & $22 / \mathrm{M}$ & Anterior & NHL & NHL \\
\hline 6 & $60 / \mathrm{M}$ & Anterior & Thymoma & Thymoma \\
\hline 7 & $16 / \mathrm{F}$ & Anterior & NHL & NHL \\
\hline 8 & $22 / \mathrm{F}$ & Anterior & Thymoma & Thymoma \\
\hline 9 & 4 months/M & Anterior & Granulomatous lymphadenitis & NGL \\
\hline 10 & $43 / \mathrm{F}$ & Anterior & Poorlydifferentiated Squamous cell carcinoma & Poorly differentiated Squamous cell carcinoma \\
\hline 11 & $47 / \mathrm{F}$ & Anterior & Thymoma & Thymoma \\
\hline
\end{tabular}

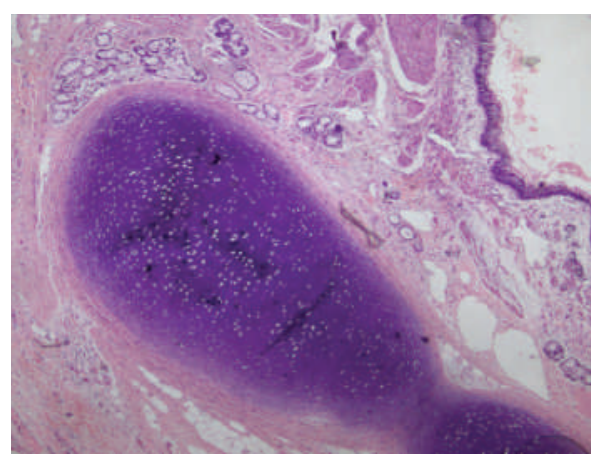

Figure 1: Mature Cystic Teratoma showing ectodermal and mesodermal tissues. (HE stain X40).

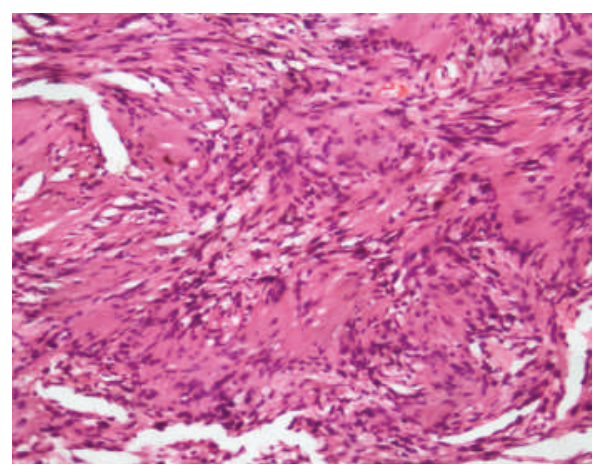

Figure 3: Hypercellular Antoni A areas seen in Schwannoma. (HE stain X100).

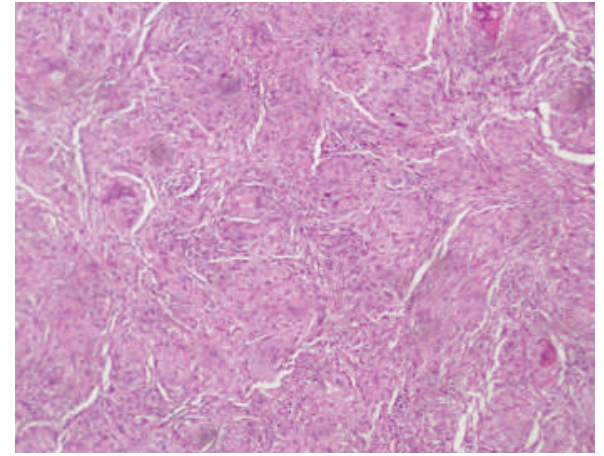

Figure 2: Granulomatous lymphadenitis showing multiple discrete granulomas formed by epitheloid histiocytes. (HE stain X40).

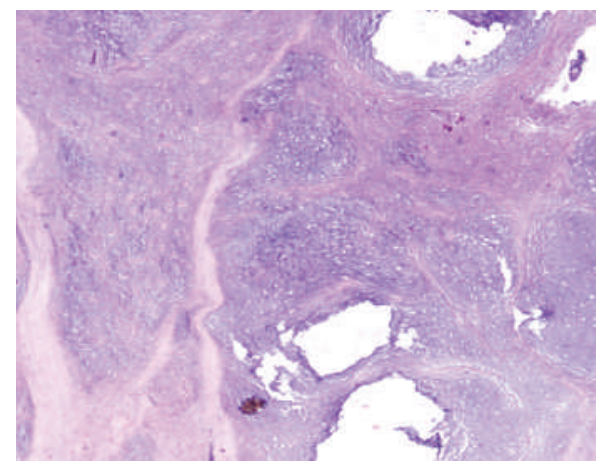

Figure 4: Chondrosarcoma showing irregularly shaped lobules of cartilage with hypercellularity. (HE stain X40).
D.C. et.al ${ }^{2}$ who demonstrated two third of all mediastinal masses as benign. Majority of lesions were seen in anterior mediastinum .In a study by Sterret $G$ et.al also majority of lesions were seen in anterior mediastinum. ${ }^{8}$ Previous studies by Mohan N. et.al ${ }^{9}$ and Vaziri M. et.al ${ }^{10}$ mediastinal lesions were more common in third decade of life which is true in our case too.

This study showed most common lesion of mediastinum was thymoma followed by NHL and Germ cell tumor. This was in contrast to study by Temes $\mathrm{R}$ et.al who showed lymphoma as commonest lesion. ${ }^{11,12}$ NHL were common in $2^{\text {nd }}-3^{\text {rd }}$ decade and germ cell in $2^{\text {nd }}-4^{\text {th }}$ decade of life which is in accordance with other studies. ${ }^{13}$ The sensitivity of FNAC in diagnosing mediastinal lesions is $72.7 \%$ in this study. This is lower than that found by Shabb N.S. et.al in his study which was about $83 \% .{ }^{13}$ Similarly to the study done by Morrissey B. et.al specificity of FNAC in diagnosing 


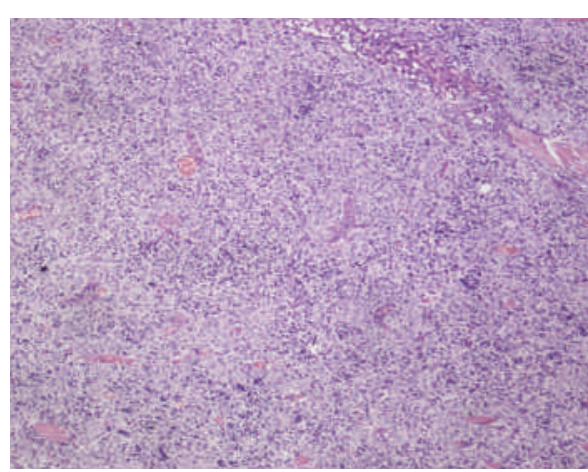

Figure 5: Sheets of neoplastic Thymic epithelial cells with scattered lypmphocytes in Thymoma (HE stain X40).

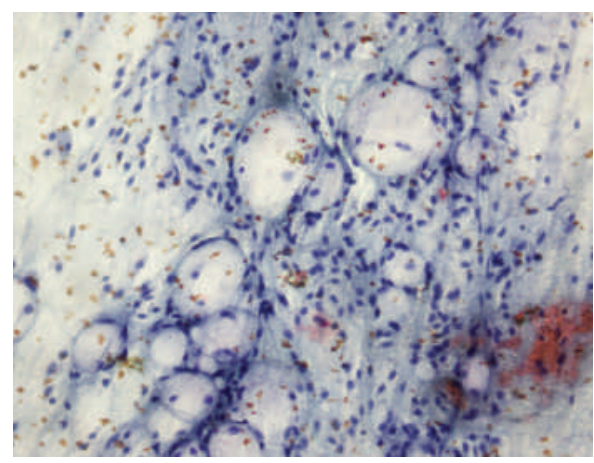

Figure 7: Prominent chicken wire vasculature with few lipoblasts in Myxoid liposarcoma (FNAC) (Pap stain X200).

malignancy is $100 \%$. This shows FNAC is fairly accurate in diagnosing malignant lesion in Mediastinum. ${ }^{5}$

\section{CONCLUSION}

Mediastinal lesion are more common in male and in anterior mediastinum with higher frequency of benign lesion most of them being Thymoma. FNAC is a good diagnostic tool in lesion of mediastinum as a first attempt to tissue diagnosis.

\section{REFERENCES}

1. Slagel DD, Powers CN, Melaragno MJ Differential diagnostic considerations and potential pitfalls in fine-needle aspiration biopsies of the mediastinum. Diagn Cytopathol, 1995;13:436-42. Crossref

2. Strollo, D.C., M.L. Rosado de Christenson, and J.R. Jett, Primary mediastinal tumors. Part 1: tumors of the anterior mediastinum. Chest, 1997;112:511-22. Crossref

3. Whitten CR, Khan S, Munneke GJ, and Grubnic S, A diagnostic approach to mediastinal abnormalities. Radiographics 2007;27:65771. Crossref

4. Shabb, NS, Fahl M, Shabb B, Haswani P, Zaatari G. Fine-needle aspiration of the mediastinum: a clinical, radiologic, cytologic, and histologic study of 42 cases. Diagn Cytopathol, 1998;19:428-36. Crossref

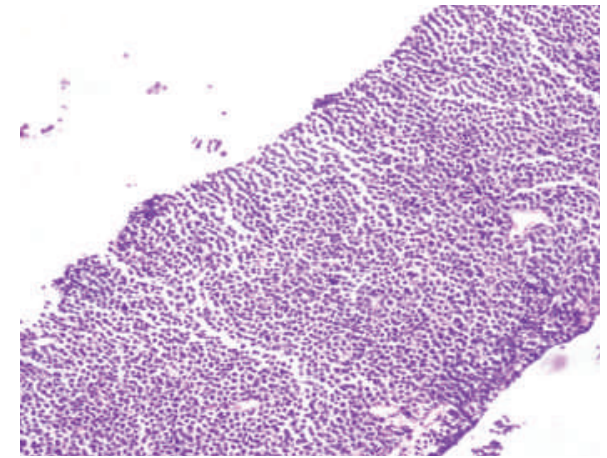

Figure 6: NHL showing sheets of monomorphic lymphoid cells. (HE stain X100).

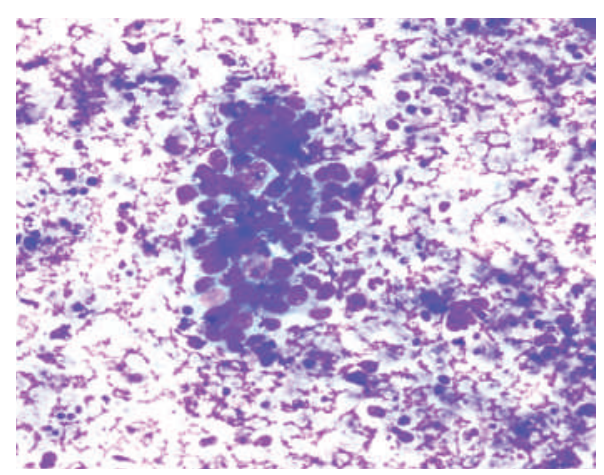

Figure 8: Tumor cells showing cytoplasmic vacuolation in Seminoma (FNAC).

Background is tigroid and shows scattered lymphocytes. ( Giemsa stain X200).

5. Morrissey, B, Adams H, Gibbs AR, Crane MD. Percutaneous needle biopsy of the mediastinum: review of 94 procedures. Thorax, 1993;48:632-7. Crossref

6. Rendina EA, Venuta F, Giacomo TD, et al. Biopsy of anterior mediastinal masses under local anesthesia. Ann Thorac Surg, 2002;74:1720-2 Crossref

7. Zafar N, MoinuddinS. Mediastinal needle biopsy. A 15-year experience with 139 cases. Cancer, 1995;76:1065-8. Crossref

8. Sterrett G, Whitaker D, Shilkin KB, Walters MN-I . The fine needle aspiration cytology of mediastinal lesions. Cancer 1983;51:127-35. Crossref

9. Mohan, N.,Rashid K, Sinha K. A Histomorphological Study of Resected Mediastinal Tumors. NJIRM, 2011;2:14-7.

10. Vaziri, M., A. Paazooki, and L.Z. Shoolami, Mediastinal Masses: Review of 105 Cases. Acta Medica Iranica, 2009;47:297-300.

11. Temes RT, Allen N, Chavez T, Crowell R, Key C, Wernly J. Primary mediastinal malignancies in children: report of 22 patients and comparison to 197 adults. Oncologist 2000;5:179-84. Crossref

12. Temes R, Chavez T, Mapel D, Ketai L, Crowell R, Key C, et al. Primary mediastinal malignancies: Findings in 219 patients. West $\mathrm{J}$ Med. 1999;170:161-6. Crossref

13. Karki S, Chalise S. Analysis of mediastinal lesions: a study of 27 cases. Journal of Patholgy of Nepal, 2011;1:114-7 Crossref 